Rezension

Sandra Folie*

\title{
Rezension zu: Mißler, Heike (2016): The Cultural Politics of Chick Lit. Popular Fiction, Postfeminism, and Representation. New York/London: Routledge. (Routledge Studies in Contemporary Literature; 18).
}


Sandra Folie, Stipendiatin der Österreichischen Akademie der Wissenschaften (DOC) am Institut für Europäische und Vergleichende Sprach- und Literaturwissenschaft, Abteilung für Vergleichende Literaturwissenschaft, Universität Wien, Sensengasse 3a, 1090 Wien, email: sandra.folie@univie.ac.at

Mißler, Heike (2016): The Cultural Politics of Chick Lit. Popular Fiction, Postfeminism, and Representation. New York/London: Routledge. (Routledge Studies in Contemporary Literature; 18).

In den letzten Jahren scheint es still geworden zu sein um Chick lit, nicht nur am Buchmarkt, sondern auch in der Forschung. Den oft proklamierten Tod des Genres, dessen Anfänge mit Bridget Jones's Diary (1996) festgesetzt werden, relativiert Heike Mißler jedoch in ihrer Monographie. Durch eine kombinierte Kontext- und Primärtext-Analyse gelingt es ihr, Chick lit als kulturelles Phänomen von anhaltender Aktualität zu positionieren.

Im ersten kontextbezogenen Teil liegt der Fokus auf der Produktion, Distribution, Verhandlung und Regulierung der Chick lit, die vor allem als Label für die Vermarktung von ,Frauenliteratur' fungierte. Aus genretheoretischer Perspektive hat sich Chick lit als überaus verwandlungsund adaptionsfähig erwiesen, weshalb sie sich nur mehr schwer an Charakteren und Plotlines festmachen lässt. Konsequenterweise legt Mißler eine aktualisierte, weite und gerade deshalb sehr brauchbare Neudefinition vor:

On the content level, chick lit is thus best defined as a female-driven quest for happiness usually told from a female point of view, and on the level of form, the most important feature is the confessional mode, marked by its intertextuality and hybridity; and most notably by its use [sic] humour and irony. (S. 33)

Auch wird die zentrale Rolle des Internets in der Rezeption und Verhandlung des Genres hervorgehoben. In Anlehnung an einen der Schlüsseltexte der Rezeptionsästhetik, Janice Radways Reading the Romance (1984), führte Mißler eine Analyse von Chick-lit-Blogs und eine kleine Umfrage unter Blogger_innen durch. Das Ergebnis zeigt, dass Fans über Blogs einen Chick-litKanon konstituieren, der in zweierlei Hinsicht als Korrektiv fungiert. Zum einen gleichen sie durch ihre Besprechungen das Desinteresse der profes- sionellen Literaturkritik aus und erzeugen Sichtbarkeit für das Genre. Zum anderen beeinflusst ihre Selektion aus der beinahe unüberschaubaren Flut an Neuerscheinungen auch künftige Publikationen. Mißler spricht von einer mehr oder weniger symbiotischen Beziehung der Chick-lit-Fangemeinde zur Buchindustrie (S. 77).

Im Fokus des zweiten Teils stehen textnahe Analysen von Primärliteratur. Die Wahl fiel mit Emma McLaughlins'/Nicola Kraus' Citizen Girl (2004), Lynn Harris' Death by Chick Lit (2006) und Erica Kennedys Feminista (2009) auf eher untypische Chick-lit-Romane. Diese eignen sich gerade aufgrund ihres genretechnischen "Versagens", weil sie Genrekonventionen überstrapazieren, gut zur Überprüfung der von Mißler vorgeschlagenen Minimaldefinition. Die Textanalysen zeigen, dass Ambiguität und subversives Potenzial akzeptierte Bestandteile der Chick lit sind, sofern sie nicht mit normativen Erwartungshaltungen wie der Heldinnen-Identifikation und dem eskapistischen Happy End konkurrieren.

Die im Fazit deklarierte Evolution der Chicklit-Formel zeigt sich laut Mißler in zwei Tendenzen. Zum einen erscheinen zunehmend Variationen des Genres von/für nicht weiße/n und/ oder queere/n Frauen; zum anderen nehmen die Karrieren der Protagonistinnen mehr Raum ein als deren Liebesbeziehungen. Dass letzterer Entwicklung weit mehr Raum zugestanden wird als ersterer, deutet auf einen Forschungs- bzw. Revisionsbedarf im Hinblick auf Chick lit als größtenteils weißes, heteronormatives Phänomen hin.

$\mathrm{Zu}$ den Verdiensten von Heike Mißlers Monographie zählt, neben der Aktualisierung des Forschungsstandes im Bereich der anglo-amerikanischen Chick lit, die präzise Verortung im übergelagerten Gender- und Genre-Diskurs. Mißler zeigt in ihrer Studie, dass Chick lit nicht nur Teil der Literatur-, sondern auch der Kulturgeschichte ist, da aktuelle Gender- und Machtdiskurse mit einfließen, die wiederum Produktion, Rezeption und Distribution der Literatur von Frauen beein- 
flussen. Dass Mißler hinter der Brandmarkung der Chick lit den Anfang vom Ende einer gegenderten Vermarktungspraxis vermutet, könnte sich in Anbetracht des unlängst ausgerufenen Clit-litLabels (Freeman 2014) allerdings als etwas zu optimistisch erweisen.

\section{Quellen:}

Freeman, Hadley (2014): Not That Kind of Girl review Lena Dunham exposes all, again. In: The Guardian, https://www.theguardian.com/books/2014/sep/30/ not-that-kind-of-girl-lena-dunham-review-memoir (12.06.2017). 